तै

G. W. Tuttle

\title{
The Low Energy Booster Project Status
}

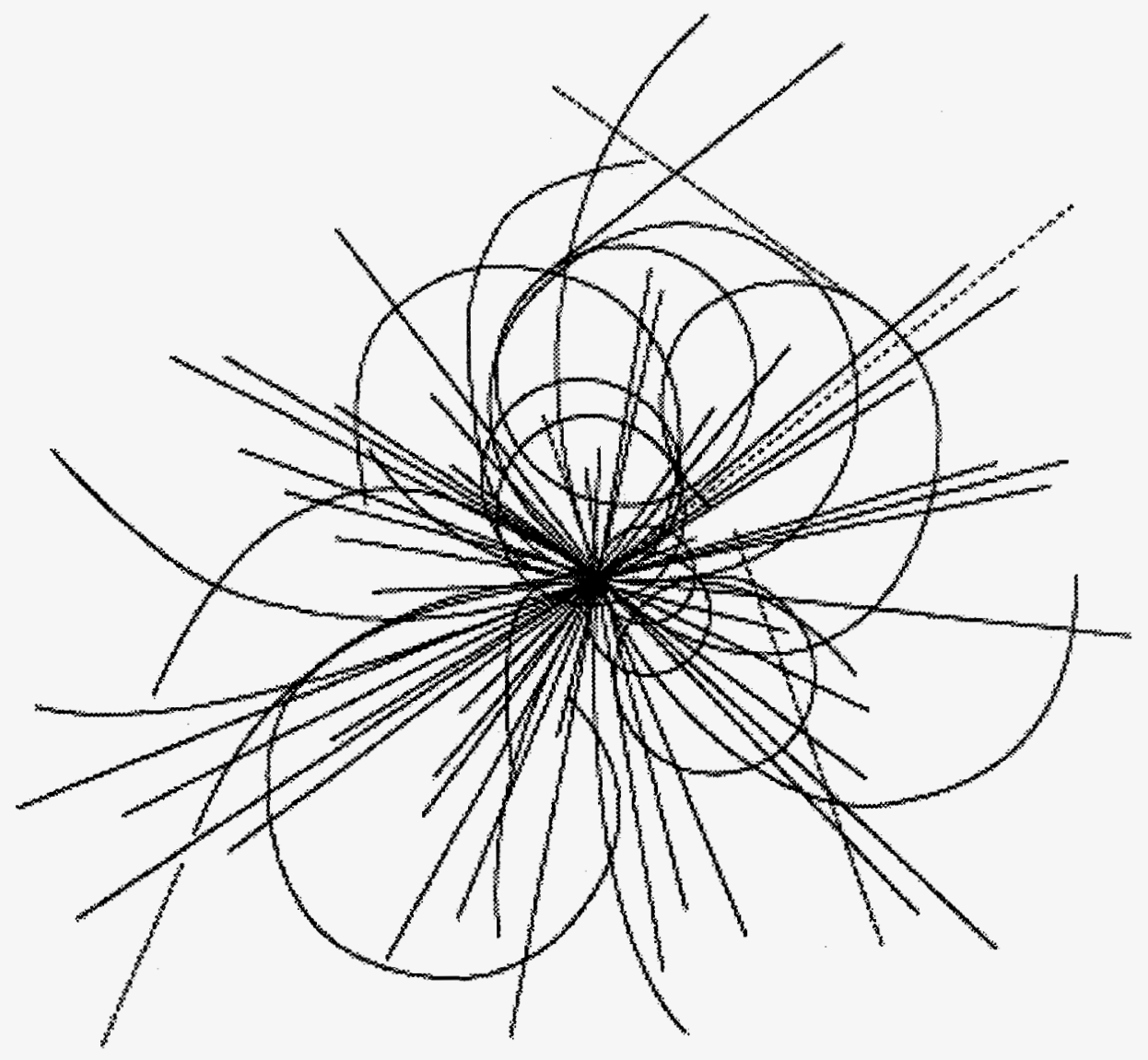

\section{Superconducting Super Collider Laboratory}

APPROVED FOR RELEASE OR DUBUICATION - OR. PATENT GROUP BY. E 


\section{Disclaimer Notice}

This report was prepared as an account of work sponsored by an agency of the United States Government. Neither the United States Government or any agency thereof, nor any of their employees, makes any warranty, express or implied, or assumes any legal liability or responsibility for the accuracy, completeness, or usefulness of any information, apparatus, product, or process disclosed, or represents that its use would not infringe privately owned rights. Reference herein to any specific commercial product, process, or service by trade name, trademark, manutacturer, or otherwise, does not necessarily constitute or imply its endorsement, recommendation, or favoring by the United States Government or any agency thereof. The views and opinions of authors expressed herein do not necessarily state or refiect those of the United States Government or any agency thereof.

Superconducting Super Collider Laboratory is an equal opportunity employer. 


\section{DISCLAIMER}

Portions of this document may be illegible in electronic image products. Images are produced from the best available original document. 


\title{
The Low Energy Booster Project Status*
}

\author{
G. W. Tuttle \\ Superconducting Super Collider Laboratory ${ }^{\dagger}$ \\ 2550 Beckleymeade Ave. \\ Dallas, TX 75237
}

May 1993

*Presented at the Fifth Annual International Symposium on the Super Collider, May 6-8, 1993 San Francisco, CA. †Operated by the Universities Research Association, Inc., for the U.S. Department of Energy under Contract No. DE-AC35-89ER40486. 


\title{
THE LOW ENERGY BOOSTER PROJECT STATUS
}

\author{
G.W. Tuttle \\ Superconducting Super Collider Laboratory* \\ 2550 Beckleymeade Ave. \\ Dallas, TX 75237
}

\section{INTRODUCTION}

In order to achieve the required injection momentum, the Superconducting Super Collider (SSC) has an accelerator chain comprised of a Linear Accelerator and three synchrotrons. The Low Energy Booster (LEB) is the first synchrotron in this chain. The LEB project has made significant progress in the development of major subsystems and conventional construction. This paper briefly reviews the performance requirements of the LEB and describes significant achievements in each of the major subsystem areas. Highlighted among these achievements are the LEB foreign collaborations with the Budker Institute of Nuclear Physics (BINP) located in Novosibirsk, Russia.

\section{LEB PERFORMANCE REQUIREMENTS}

The LEB is a rapid cycling $(10 \mathrm{~Hz})$ synchrotron and has a unique triangular shaped, three-fold symmetric lattice. The primary design challenge for the LEB is the preservation of the transverse beam emmittance at low energy, the difficulty being a substantial spacecharge tune spread. The lattice was designed to avoid transition, $\gamma_{t}=22.14$, in an effort to mitigate the emmitance problem. The performance requirements are outlined in Table 1.

Table 1. Low Energy Booster Performance Requirements.

\begin{tabular}{lcl}
\hline \multicolumn{1}{c}{ Parameter } & Requirement & \multicolumn{1}{c}{ Units } \\
\hline Injection Momentum & 1.22 & $\mathrm{GeV} / \mathrm{c}$ \\
Extraction Momentum & 12.0 & $\mathrm{GeV} / \mathrm{c}$ \\
Particles/Bunch & $1 \times 10^{10}$ & \\
Input $\varepsilon_{\text {rms-normalized }}$ & 0.3 & $\pi \mathrm{mm}-\mathrm{mrad}$ \\
Output $\varepsilon_{\text {rms-normalized }}$ & 0.6 & $\pi \mathrm{mm}-\mathrm{mrad}$ \\
\hline
\end{tabular}

\footnotetext{
* Operated by the Universities Research Association, Inc., for the U. S. Department of Energy under Co No. DE-AC35-89ER40486.
} 


\section{MAGNET STATUS}

The LEB includes a complex lattice of 186 main magnets, 90 two meter dipoles and 96 quadrupoles of varying lengths, and 244 corrector magnets including: 90 dipoles, 94 quadrupoles ( 90 trim and 4 skew), 48 sextupoles, and 12 skew sextupoles, and specialty magnets used for the injection, the extraction, and the transport of the beam. Although the magnets were primarily designed by the SSC, some aspects of the design are the result of a BINP collaboration .

The SSC signed an agreement with BINP to build and test a prototype of the main dipole and quadrupole magnet. BINP has built the main dipole and will begin testing in May 1993. BINP has also built and tested a prototype main quadrupole. The SSC also commissioned Lawrence Berkeley Laboratory (LBL) to build a prototype quadrupole and Stanford University to build a prototype main dipole magnet, all based on the same design.

Lawrence Berkeley Laboratory (LBL) has built and tested the prototype main quadrupole magnet and Stanford University is expected to complete the prototype main dipole in May 1993. The test results on both main quadrupole prototypes indicate that the design will meet or exceed specification and only minor structural support changes are contemplated. BINP and their subcontractors are scheduled to start full-rate production of the main dipole and quadrupole magnets in late 1993.

A prototype of the two basic types of quadrupole corrector magnets (high field and low field) were built by the SSC. The quadrupole correctors design makes use of the same lamination as the main quadrupole magnet. A sextupole corrector magnet prototype and a dipole corrector magnet prototype were also built by the SSC. Some of the early testing was accomplished at Los Alamos National Lab and Lawrence Berkeley Laboratory. Subsequently all corrector magnets have been tested at the SSC. The test results to date reveal a promising design and required only minor modifications the production design.

BINP is currently building anoter set of prototype corrector magnets based on the modified SSC design, under an agreement similar to the main magnet agreement. BINP and their subcontractors are scheduled to start full-rate production of the corrector magnets in early 1994.

\section{POWER SYSTEM STATUS}

The SSC has completed specifying the major components of the Ring Magnet Power System. This system will be capable of delivering 4000 amperes of current to a resonant circuit comprised of the main magnets, twelve $40 \mathrm{mH}$ Energy Storage Inductors (ESI), and twelve $18 \mathrm{mF}$ Capacitor Banks, tuned to resonate at $10 \mathrm{~Hz}$.

Scheduled to begin delivery in May 1993, the ESIs will be the first production LEB components to arrive on site. BINP designed, and arranged for the fabrication of the ESIs in Ekaterinberg, (Siberia) Russia The ESIs has been verified and two production units have been tested. The other component of the LC circuit, the Capacitor Bank Assembly, is in the source selection phase and several outstanding proposals have been received from Industry.

The remaining portion of the LEB power system are elements of a larger acquisition strategy to buy similar power system components for the entire injector chain. These include the $15 \mathrm{kV}$ switch gear and transformers, the rectifier converters cabinets, thyristors, and passive filters. The LEB phase of these procurements will be out for competition to industry in the next $12-18$ months.

The corrector power supplies, also operating at $10 \mathrm{~Hz}$, are lower capacity operating at load currents as low as 3.5 Amperes, for the skew sextupole, and as high as 100 Amperes for the high field quadrupole. The corrector power supplies are of the rack mounted variety and the present design includes powering a series of similar amplifiers from a single bulk power supply. This procurement is planned for competition in late 1993. 


\section{RF SYSTEM STATUS}

The RF system is the most technically challenging LEB system, the principal challenge being the RF tuner/cavity design. The LEB cavity is a quarter wave coaxial resonator with the accelerating gap at the high voltage end and a ferrite tuner at the high current end. Tuning is accomplished by varying the permeability of the ferrite. The LEB RF system is required to provide a circumferential voltage of $765 \mathrm{kV}$ and tune over a substantial range $(47.5-59.8 \mathrm{MHz})$. Although the baseline design is 8 cavities, lattice space is available for a maximum of 16 cavities, should the required gap voltages and the associated heating problems preclude the 8 cavity design .

The perpendicularly biased field design for the LEB tuner results in a higher magnetic $Q$ in the ferrite, thereby allowing higher gap voltages then can be achieved with a conventional parallel biased design. Even so, substantial heat is still developed due to the losses. This has lead to two designs: a liquid cooled tuner which was designed and built by the SSC and a conduction cooled design which is a modification of the SSC design produced by BINP.

The conduction cooled design has been tested at the SSC and has demonstrated good performance. However a failure recently occurred at higher gap voltages, apparently due to a void in the elastoner used to bond the ferrites, which resulted in arcing. A failure analysis is being conducted by the SSC and BINP to determine the viability of the design.

The Liquid cooled tuner is currently being assembled and testing should begin in May 1993. Upon completion of the prototype testing, a final design will be selected and a buildto-print procurement will be initiated. The tuner/cavity assembly also includes a $4 \mathrm{CW} 150,000$ tetrode which is mounted directly on the accelerating cavity.

The RF tuner/cavity is supported by an array of power supplies. The largest being the Anode Power supply which is an oil filled $400 \mathrm{KVA}$ rectifier/transformer. The tuner is biased by another power supply which is tap selectable $(150 \mathrm{Vdc}-300 \mathrm{Vdc})$ in $50 \mathrm{~V}$ increments, and capable of providing $1500 \mathrm{~A}$ of output current. These RF power supplies will be put out for competition in the next 12 months. A complex low-level RF and supervisory control system is also being developed at the SSC in cooperation with Los Alamos National Laboratory.

\section{VACUUM SYSTEM STATUS}

The LEB beam line is defined by 198 vacuum chambers which fit into the aperture of the main and corrector magnet packages. A prototype of each major chamber was been built by industry and has been tested at the SSC. A build-to-print procurement for 198 chambers and the associated bellows will be issued within the next 12 months.

The $10^{-7}$ Torr vacuum environment within the chamber will be maintained by 90 noble diode ion pumps. These pumps will be supported by a number of power supplies and controllers located in racks in the LEB surface buildings. The ion pumps and associated support equipment including: thermocouple gauges, cold cathode gauges, and Turbo Molecular Pump carts obtained in a build-to-specification procurement within the next 12 months.

\section{INSTRUMENTATION SYSTEM STATUS}

Another prominent feature of the beam line is the more than 100 monitors that are located in strategic locations throughout the LEB lattice. These monitors and their associated electronics characterize the beam position, beam profile, beam current, bunch length and other vital beam information. The instrumentation system also includes a number of beam loss monitors, located on the tunnel walls, which detect any substantial beam losses. All monitors and their associated electronics are in various stages of design and 
development. The majority of the LEB instrumentation system will be procured, at the component level, via build-to-print specifications in the next 18-24 months.

\section{CONTROL SYSTEM STATUS}

The LEB, like all other machines, will be centrally controlled from the Accelerator Main Control Room (AMCR). The LEB will communicate with the AMCR via a SONET fiber optic backbone that supports a minimum OC-3 bandwidth. The LEB interfaces to the SONET backbone via Add Drop Multiplexers (ADM) located in each of the LEB surface buildings. The ADMs will interface directly to the individual subsystems located within the building. The LEB also includes a precision timing system which will be the basis for synchronizing all LEB subsystems. Most of these systems will be procured in a build-tospecification procurement in the next 18-24 months.

\section{CONVENTIONAL CONSTRUCTION STATUS}

The most visibly exciting LEB progress to date is that of the $570 \times 3.7 \times 3$ meter tunnel. The construction began in January 1993 and is scheduled to be completed by Mid 1994. The construction of the six primary surface buildings, one located at each arc and one located at each straight, and the installation building will begin in the next few months.

\section{SUMMARY}

Although technical challenges remain in areas such as the RF System, the LEB design and development is progressing exceeding well. Most major subsystems will be procured in the next year and the tunnel will be ready for installation activities in early 1994. The LEB is currently scheduled to be operational in 1996.

\section{REFERENCES}

1. E.D. Courant, A.A. Garren., and U. Wienands, "Low Momentum Compaction Lattice Study for the SSC Low Energy Booster," Proceedings of the IEEE Particle Accelerator Conference, San Francisco, CA. (1991).

2. R.C. York et al., "Low Energy Booster: A Status Report," Proceedings of the 1991 IEEE Particle Accelerator Conference, San Francisco, CA.(1991).

3. R.L. Poirier, T. Enegren and C. Haddock, "Perpendicular Biased Ferrite Tuned RF Cavity for the TRIUMF KAON Factory Booster Ring," IEEE Particle Accelerator Conference, Chicago, IL (1989).

4. C. Jach, "Switchable $10 \mathrm{~Hz} / 1 \mathrm{~Hz}$ LEB Magnet Power Supply System," IEEE Particle Accelerator Conference, San Francisco, CA.(1991).

5. R. Winje, "Equipment Acquisition Plans or the SSCL Magnet Excitation Power System," This Conference, San Francisco, CA.(1993). 